\title{
ARTICLE OPEN Hearing loss and its association with occupational noise exposure among Saudi dentists: a cross-sectional study
}

\author{
Bander M Alabdulwahhab ${ }^{1}$, Raneem I Alduraiby ${ }^{2}$, May A Ahmed ${ }^{2}$, Lamya I Albatli ${ }^{2}$, Maram S Alhumain ${ }^{2}$, Nada A Softah ${ }^{2}$
} and Shaza Saleh ${ }^{3}$

OBJECTIVES/AIMS: Dental practitioners are prone to hearing loss due to noise exposure encountered in dental clinics. The aim of this study was to determine whether the persistent high-frequency sounds produced by the dental equipment could cause hearing decrement among the Saudi dental practitioners.

MATERIALS AND METHODS: This cross-sectional study included 38 randomly selected Saudi dentists from different specialties who were exposed to noise during working hours and 38 individuals as a control group. The participants underwent four audiometric tests that included an otoscopic examination, tympanometry, pure tone audiometry and the distortion product otoacoustic emissions (DPOAE) test.

RESULTS: The data revealed that $\sim 15.8 \%$ of the dentists and $2.6 \%$ of the control group had some hearing loss. No significant difference was found between the two groups in the pure tone audiometry test; however, qualitative analysis revealed a higher percentage of hearing loss among the dentists' group as compared with their control counterparts. A statistically significant difference was found in DPOAEs between the two groups in the left ear $(P=0.002)$, and between the right and left ears $(P=0.005)$. DISCUSSION: In the present cross-sectional study, the prevalence of hearing loss among dentists as assessed with the pure tone audiometry test was $15.8 \%$. Which was in accordance with a previous study performed by Khaimook et al., which revealed the prevalence of hearing loss in dental personnel to be $17.7 \%$; however, no significant differences were observed compared to the control group in both studies. The otoacoustic emission test in the left ear exhibited significant changes. These changes could have been due to the presence and continuity of the sounds produced by high- and low-velocity suction devices on the left side of the dental unit knowing that $97 \%$ of the dentists are right handed.

CONCLUSION: Evidence suggests that noise from dental clinics can cause hearing problems, which had a greater effect on the left ear than the right; however, these problems are not severe in nature. Noise-induced hearing loss was more prevalent among the dentists than the control group.

BDJopen (2016) 2, 16006; doi:10.1038/bdjopen.2016.6; published online 4 November 2016

\section{INTRODUCTION}

According to the national institute for occupational safety and health, noise has been identified as one of the 10 leading causes of work-related diseases or injuries. ${ }^{1}$ The amount of damage depends primarily on the intensity of the noise and the duration of the exposure. Noise-induced hearing loss can be temporary following short-term exposure to noise, with the return of normal hearing after a period of rest. ${ }^{2}$ Injury to the ear due to noise occurs in two different manners that depend on the type of exposure. High-level short-duration exposures to more than 140 decibel ( $d B$, i.e., a unit that measures sound intensity) can stretch the delicate inner ear tissues beyond their elastic limits and then rip or tear them apart. This type of damage (acoustic trauma) develops rapidly and causes an immediate and permanent hearing loss. The second type of injury occurs because of exposure to noise between 90 and $140 \mathrm{~dB}$, which causes metabolic rather than mechanical damage to the cochlea, and this damage is related to the level and duration of exposure. ${ }^{3}$ The factors that affect the degree and extent of hearing impairment include the intensity and type of noise, the period of exposure each day, total work duration, distance from the source, and individual age and susceptibility. ${ }^{4}$

The Occupational Safety and Health Administration of the United State Department of Labor demands that employers develop and implement a noise-monitoring programme when employees are exposed to noise equal to or exceeding $85 \mathrm{~dB}$ for more than eight working hours. If this situation occurs, Occupational Safety and Health Administration requires employers to inform employees to establish and maintain an audiometric testing protocol, and to train workers how to prevent occupational hearing loss. When hazardous noise have not yet been eliminated, Occupational Safety and Health Administration also requires employers to provide hearing protection and to ensure that the workers utilise that protection. ${ }^{2}$

Pure tone audiometry is generally the first quantitative hearing test that is performed to assess the nature and degree of hearing loss in adults and children over 4 years of age to properly plan the most appropriate intervention because this test determines the faintest tones a person can hear at selected frequencies from low to high. 5,6

\footnotetext{
${ }^{1}$ Restorative Department, Royal Clinics Department of Dental Services, Part Time Faculty at Riyadh Colleges of Dentistry and Pharmacy, Riyadh, Saudi Arabia; ${ }^{2}$ Riyadh Colleges of Dentistry and Pharmacy, Riyadh, Saudi Arabia and ${ }^{3}$ King Faisal Specialist Hospital and Research Centre, Riyadh, Saudi Arabia.

Correspondence: LI Albatli (lamyaalbatli@live.com)

Received 21 April 2016; accepted 27 July 2016
} 
Otoacoustic emissions (OAEs) permit the early detection of inner ear abnormalities that are associated with a wide variety of diseases and disorders, including non-pathologic etiologies, such as noise exposure and aging. Changes in outer hair cell length generate energy within the cochlea that contributes to hearing sensitivity and the ability to distinguish small differences in the frequencies of sounds. ${ }^{7}$

People are accustomed to everyday normal noise that is constantly present all around them. Similar to other working professionals, dental practitioners are exposed to many occupational hazards; hearing loss is definitely one such occupational hazard due to the noise that is constantly present during their work. ${ }^{8}$ Instruments in the dental office, such as high-speed turbine hand pieces, low-speed hand pieces and high-velocity suction devices, produce dangerously loud noises that may contribute to hearing loss. Long-term exposure to noise levels of greater than $80-85 \mathrm{~dB}$ is associated with an increased risk of hearing loss. ${ }^{9}$ Kilpatrick $^{10}$ provided a list of the $\mathrm{dB}$ ratings of different office instruments and equipment and reported levels of 70-92 dB for high-speed turbine hand pieces, $86 \mathrm{~dB}$ for ultrasonic scalers and $74 \mathrm{~dB}$ for low-speed hand pieces.

A previous study by Alwazzan et al. ${ }^{11}$ that sought to determine the prevalence of hearing problems among dentists in Saudi Arabia concluded that all dental personnel exhibit roughly the same incidence of symptoms, which include tinnitus, speech discrimination difficulties and difficulties with speech discrimination in the presence of background noise; moreover, dental technicians were found to be the most affected group.

The aim of this study was to determine whether the persistent high-frequency sounds produced by the dental equipment could cause hearing decrement among the Saudi dental practitioners.

\section{MATERIALS AND METHODS}

\section{Study group}

This cross-sectional study was conducted from March to December 2015. Thirty-eight dentists from different specialties who work at various governmental hospitals and private clinics that were exposed to occupational noise and a control group of thirty-eight matched nondental professionals were recruited; matching was done based on age, gender and whether that participant was a smoker/non-smoker. Both sample groups were selected randomly while observing the matching criteria for the control group only

The inclusion criteria for the experimental group included dentists who had been practicing dentistry for more than 5 years, which includes 2 years of preclinical practice. For the control group, the inclusion criterion was individuals who had not been exposed to noise during work hours. Both sample groups included individuals between the ages of 25 and 40 years. The exclusion criteria for both groups included daily loud music exposure for more than $3 \mathrm{~h},{ }^{12}$ history of chronic ear disease, ear surgery, ear trauma, ototoxic drugs, diabetes, previous sensorineural hearing loss, any hereditary factors and treatment with radiation or chemotherapy.

\section{Sample design}

This study has received a formal review and approval from the ethics committee of Riyadh Colleges of Dentistry and Pharmacy. The potential participants were approached either by telephone or in person to explain the effects of instrument noise on hearing and were asked to be part of this cross-sectional study. After providing written informed consent, the participants underwent an otoscopic examination and tympanometry by an audiology specialist at Magrabi Hospitals and Centers. If abnormal findings were observed, the individual was excluded from further testing. Subsequently, the participants who fulfilled the inclusion criteria completed a demographic questionnaire and underwent pure tone audiometry and distortion product otoacoustic emission (DPOAE) testing.

The collected data included age group $(25-28,29-32,33-36$ and $37-40$ years of age), gender, years of practice $(5-8,9-12$ or $\geqslant 13$ years), actual number of hours exposed to loud noise each week $(\leqslant 27,28-36$ or $\geqslant 37 \mathrm{~h})$, days of exposure per week $(3,4,5$ or 6 days) and whether the dentists are left-handed or right-handed (Table 1).

\begin{tabular}{|lc|}
\hline Table 1. Participants' demographic data & \\
\hline Demographics & $\mathrm{n}^{*}=38 ; \%$ \\
\hline Gender & \\
Female & $15(39.47)$ \\
Male & $23(60.52)$ \\
& \\
Age (years) & $17(44.73)$ \\
$25-28$ & $11(28.94)$ \\
$29-32$ & $6(15.78)$ \\
$33-36$ & $4(10.52)$ \\
$37-40$ & \\
Working days per week & $2(5.26)$ \\
3 & $11(28.94)$ \\
4 & $19(50)$ \\
5 & $6(15.78)$ \\
6 & \\
Working hours per week (h) & $13(34.21)$ \\
$\leqslant 18-27$ & $11(28.94)$ \\
$28-36$ & $14(36.84)$ \\
$\geqslant 37 \mathrm{~h}$ & \\
Years of experience & $19(50)$ \\
$5-8$ & $11(28.94)$ \\
$9-12$ & $8(21.05)$ \\
$\geqslant 13$ & \\
Handiness & $37(97 \%)$ \\
Right-handed & $1(3 \%)$ \\
Left-handed & \\
\hline Abbreviation: $\mathrm{n}^{*}$, number of dentists. & \\
& \\
\hline & \\
& \\
& \\
& \\
& \\
&
\end{tabular}

Test battery

Pure tone audiometry. The audiometric examinations were performed using an audiometer (GSI 61, Grason Stadler, Minneapolis, MN, USA) in a $2 \times 2 \mathrm{~m}$ double-walled sound booth that was calibrated according to the standards of the International Standard Organization (1964). Air conduction hearing thresholds were measured by pure tone audiometry at the following frequencies: $250 \mathrm{~Hz}, 500 \mathrm{~Hz}, 750 \mathrm{~Hz}, 1 \mathrm{kHz}, 2 \mathrm{kHz}, 3 \mathrm{kHz}, 4 \mathrm{kHz}$, $6 \mathrm{kHz}$ and $8 \mathrm{kHz}$. The pure tone averages at 4,6 and $8 \mathrm{kHz}$ reflect the frequency range that is most susceptible to noise-induced hearing loss. Losses of more than $25 \mathrm{~dB}$ in these frequencies are usually considered abnormal (see Figure 1).

Distortion Product Otoacoustic Emissions. Otoacoustic emission tests (DPOAE, OAE System, Pleasanton, CA, USA) are used to determine cochlear status and particularly hair cell function. ${ }^{13}$

\section{Statistical analysis}

The IBM SPSS computer software (Statistical Package for the Social Sciences, version 20.0, SPSS Inc., Chicago, IL, USA) for Windows was used to perform the analyses. The 3Power G3.1 software (G*Power: Statistical Power Analyses Heinrich-Heine-University Düsseldorf, Düsseldorf, Germany) was used to conduct power analysis and determine the number of the required sample size, which was 25 . Wilcoxon test was used to determine whether the differences in the pure tone audiometry and OAE test results were significantly different between the dentists and the control group. The level of significance was defined as equal to or less than 0.05 .

Qualitative analysis of pure tone audiometry results was conducted based on the characterisation criteria proposed by Jensen et al. ${ }^{14}$ which was used to investigate noise-induced hearing loss among musicians of symphony orchestras. They adopted a rather strict criterion for normal hearing, and more specific criteria for the degree of the noise notch if present (see Figure 2). 

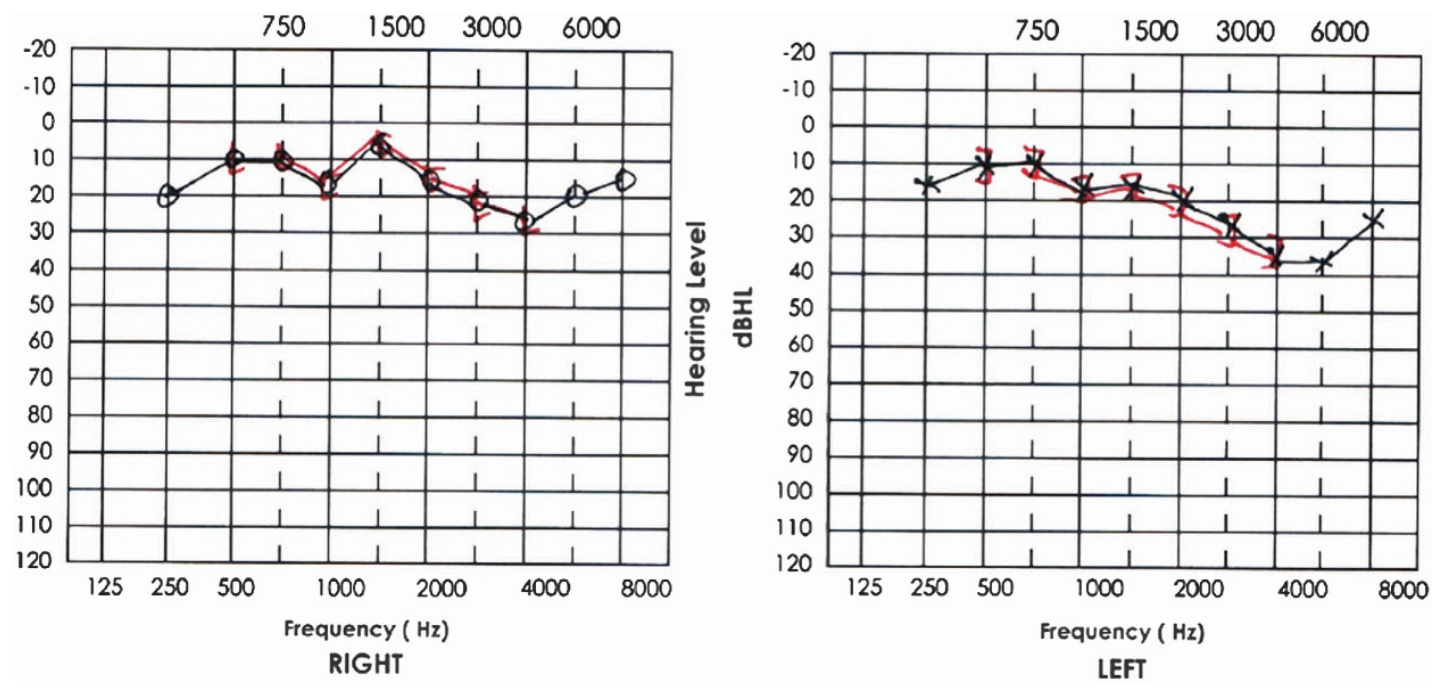

Figure 1. Audiograms showing results more than $25 \mathrm{~dB}$ in high frequencies in the right and left ear.

- Normal hearing $(N)$ : hearing threshold levels better than or equal to $15 \mathrm{~dB} \mathrm{HL}$ at all measured frequencies (i.e. 0.5 , $1,2,3,4,6,8 \mathrm{kHz})$.

- Notch moderate (NM): maximum threshold level of 3, 4, and $6 \mathrm{kHz}$ between 15 and $20 \mathrm{~dB}$ poorer than the puretone average of thresholds at $0.5,1$ and $2 \mathrm{kHz}$ and at least $10 \mathrm{~dB}$ poorer than the threshold level at $8 \mathrm{kHz}$. This is similar to Niskar et al. (2001) criterion of a noise notch in adolescents.

- Notch profound (NP): similar to NM, but maximum threshold level of $3,4,6 \mathrm{kHz}$ at least $25 \mathrm{~dB}$ poorer than the pure-tone average of thresholds at $0.5,1$ and $2 \mathrm{kHz}$.

- Sloping loss (SL): maximum threshold level of 3, 4, $6 \mathrm{kHz}$ at least $5 \mathrm{~dB}$ poorer than the pure-tone average of thresholds at $0.5,1$ and $2 \mathrm{kHz}$ and threshold level at $8 \mathrm{kHz}$ at least $5 \mathrm{~dB}$ poorer than the maximum threshold level at 3,4 , and $6 \mathrm{kHz}$.

- Flat loss (FL): audiograms which do not fall into the above mentioned categories, with no hearing thresholds exceeding $30 \mathrm{~dB}$ at all measured frequencies.

- Rest (R): all audiograms that do not match the characteristics of the above described categories.

Figure 2. Criteria for the characterization of the pure-tone audiograms and the degree of the noise notch adapted from Jensen et al. ${ }^{14}$

\section{RESULTS}

The ages of the 38 dentists and the 38 participants of the control group ranged from 25 to 40 years, and the sample included $23(61 \%)$ males and 15 (39\%) females (Table 1). The prevalence of hearing loss (as assessed by any decrease in hearing of more than $25 \mathrm{~dB} \mathrm{HL}$ in the pure tone audiometry tests) was six participants in the group of 38 dentists (15.8\%) and one participant in the control group of 38 participants (2.6\%). When the more stringent criteria of $15 \mathrm{~dB}$ hearing loss $(\mathrm{HL})^{14}$ was applied, it revealed that 29 of the dentists (76\%) and 23 participants from the control group (60\%) had some type of hearing loss.

No significant difference was observed between the two groups in the pure tone audiometry results at the following frequencies: $500 \mathrm{~Hz}, 1 \mathrm{kHz}, 2 \mathrm{kHz}, 4 \mathrm{kHz}, 6 \mathrm{kHz}$, and $8 \mathrm{kHz}$. Moreover, there were no significant differences between dentists and the matched control group in terms of noise-induced hearing loss in the right and left ears separately or in both ears combined (Table 2).

\begin{tabular}{|c|c|c|c|c|c|}
\hline \multirow[t]{3}{*}{$\begin{array}{l}\text { Ear of } \\
\text { participant }\end{array}$} & \multirow[t]{3}{*}{$\begin{array}{l}\text { Dentist } \\
\left(\mathrm{n}^{*}=38\right)\end{array}$} & \multirow[t]{3}{*}{$\begin{array}{l}\text { Control } \\
\left(\mathrm{n}^{*}=38\right)\end{array}$} & \multirow{2}{*}{\multicolumn{2}{|c|}{$\begin{array}{c}\begin{array}{c}\text { Pure tone } \\
\text { audiometry }\end{array} \\
\text { P*-value }\end{array}$}} & \multirow{3}{*}{$\begin{array}{c}\begin{array}{c}\text { Otoacoustic } \\
\text { emission }\end{array} \\
\mathrm{P}^{*} \text {-value }\end{array}$} \\
\hline & & & & & \\
\hline & & & \multicolumn{2}{|c|}{$\begin{array}{cc}\text { Low } & \text { High } \\
\text { frequency frequency }\end{array}$} & \\
\hline Right & 38 & 38 & 0.387 & 0.321 & 0.355 \\
\hline Left & 38 & 38 & 0.293 & 0.217 & 0.003 \\
\hline $\begin{array}{l}\text { Both ears } \\
\text { (right and left) }\end{array}$ & 38 & 38 & 0.173 & 0.132 & 0.005 \\
\hline
\end{tabular}

The assessments of noise-induced hearing loss with the DPOAE tests revealed no significant differences between the two groups in the right ear $(P=0.355)$, but a significant difference was found for the left ear $(P=0.002)$ and in both ears combined $(P=0.005)$ (Table 2). The mean values for the pure tone audiometry and the DPOAE tests for both dentists and their control counterparts are illustrated in Tables 3 and 4.

Qualitative analysis of the audiograms as proposed by Jensen et al. ${ }^{14}$ showed different patterns among the dentists as compared to their control counterparts. For the right ear, $5.2 \%$ of the dentists exhibited sloping loss, and $60.5 \%$ had flat loss. For the left ear, $7.8 \%$ had a moderate notch, and $50 \%$ had flat loss. On the other hand, $42.1 \%$ of the control group showed normal hearing in the right ear, and $52.6 \%$ had normal hearing in the left ear (see Table 5).

\section{DISCUSSION}

Occupational noise-induced hearing loss is defined as bilateral sensorineural hearing loss that develops gradually over a period of several years because of exposure to continuous or intermittent loud noise in the work place. ${ }^{15}$

Hearing loss due to aging or genetic factors is not preventable. In contrast, noise-induced hearing loss can be prevented by the use of protective equipment in noisy environments, including ear 
Table 3. Illustrates descriptive statistics of all the variables for the dentists

\begin{tabular}{|c|c|c|c|c|c|c|c|}
\hline \multirow[t]{2}{*}{ Ear of participant } & \multirow[t]{2}{*}{ Dentist $\left(\mathrm{n}^{*}=38\right)$} & \multicolumn{4}{|c|}{ Pure tone audiometry } & \multicolumn{2}{|c|}{ Otoacoustic emission } \\
\hline & & \multicolumn{2}{|c|}{ Low frequency } & \multicolumn{2}{|c|}{ High frequency } & Std & Mean \\
\hline Right & 38 & 5.96077 & 11.2916 & 6.92840 & 11.6429 & 8.11467 & 12.6194 \\
\hline Left & 38 & 6.24268 & 9.9379 & 8.00434 & 11.5600 & 7.95475 & 13.5362 \\
\hline
\end{tabular}

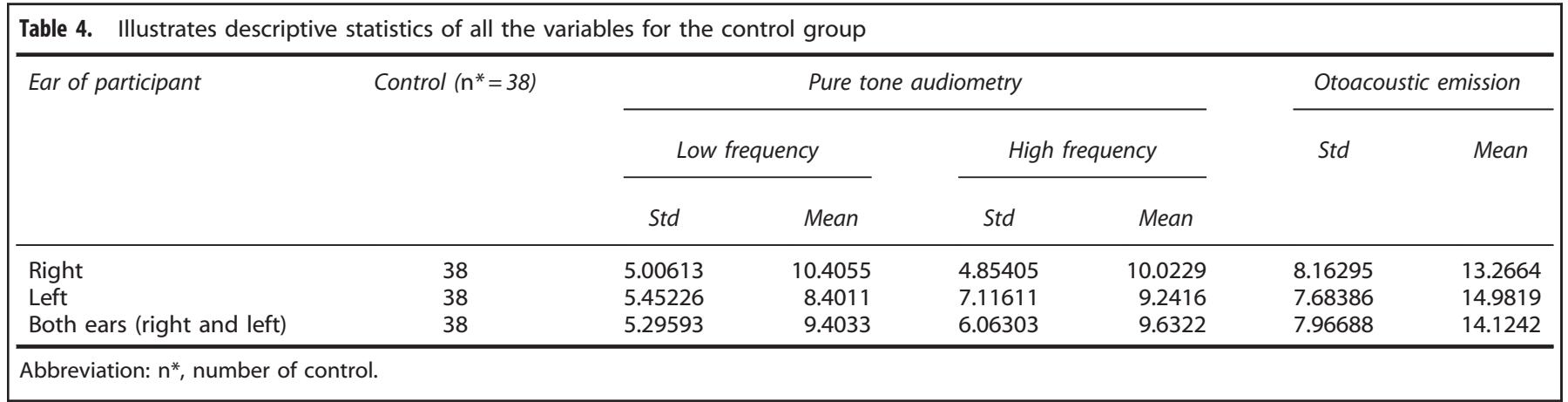

\begin{tabular}{|c|c|c|c|c|c|c|c|c|c|c|c|c|}
\hline \multirow{2}{*}{$\begin{array}{l}\text { Ear of } \\
\text { participant }\end{array}$} & \multicolumn{6}{|c|}{ Dentist, $\mathrm{n}=38$ (\%) } & \multicolumn{6}{|c|}{ Control, $\mathrm{n}=38$ (\%) } \\
\hline & Normal & $\begin{array}{c}\text { Notch } \\
\text { moderate }\end{array}$ & $\begin{array}{l}\text { Notch } \\
\text { profound }\end{array}$ & Sloping loss & Flat loss & Rest & Normal & $\begin{array}{l}\text { Notch } \\
\text { moderate }\end{array}$ & $\begin{array}{l}\text { Notch } \\
\text { profound }\end{array}$ & Sloping loss & Flat loss & Rest \\
\hline Right ear & 13 (34.2\%) & 0 (0\%) & $0(0 \%)$ & 2 (5.2\%) & $23(60.5 \%)$ & $0(0 \%)$ & $16(42.1 \%)$ & $0(0 \%)$ & $0(0 \%)$ & 1 (2.6\%) & $21(55.2 \%)$ & $0(0 \%)$ \\
\hline
\end{tabular}

plugs and ear muffs. ${ }^{16}$ Unfortunately, none of the participants in this study were using any type of ear protection, potentially due to discomfort, fear that the protective device may interfere with communication, inconvenience, negative feedback from co-workers or patients and the belief that noise levels from dental instruments will not damage their hearing. ${ }^{16}$

A study that sought to determine the prevalence of hearing problems among dentists in Saudi Arabia concluded that all dental personnel exhibit roughly similar incidences of symptoms; i.e., $16.6 \%$ had tinnitus, $14.7 \%$ had speech discrimination difficulties and $63 \%$ had problems with speech discrimination in the presence of background noise. The incidences of symptom were similar because all dental personnel are exposed to similar noise levels. ${ }^{11}$

The occurrence of hearing loss due to prolonged exposure to noise levels greater than $85 \mathrm{~dB}$ without the use of any type of ear protection is well documented in the literature. ${ }^{17-19}$ Therefore, the noise generated in the dental clinic should not be underestimated. $^{20}$ The sources of dental sounds that can be treated as potentially damaging to hearing include high-speed turbine hand pieces, high-velocity suction devices, ultrasonic scalers and other mixing devices. ${ }^{8}$

Altinoz et al. ${ }^{21}$ noted that personnel who work in noisy environments should not engage in noisy activities immediately following the workday. These authors stated that 'the ear begins to recover its hearing ability when it is allowed to rest'.
The prevalence of noise-induced hearing loss among dental personnel has been reported to range from 7 to $16 \%$ in the literature. ${ }^{22-24}$ The study performed by Khaimook et al. ${ }^{15}$ revealed the prevalence of hearing loss in dental personnel to be $17.7 \%$; however, no significant differences were observed compared with the control group.

In the present cross-sectional study, the prevalence of hearing loss among dentists as assessed with the pure tone audiometry test was $15.8 \%$, which did not significantly differ from the results observed in the control group. Prevalence with more stringent criteria among dentists was $76 \%$. A significant difference may have been observed with a larger sample. Regarding the DPOAEs that were used to compare the two groups, the left ear exhibited significant changes that could have been due to changes in the outer hair cell lengths. These changes could also have been due to the presence and continuity of the sounds produced by high- and low-velocity suction devices on the left side of the dental unit, considering that $97 \%$ of the dentists in this study were righthanded. Undoubtedly, the degree of risk to the dental practitioner depends upon certain factors such as the intensity of the sound and the duration of exposure. . $^{85}$

In an article written by Khaimook et al., ${ }^{15}$ the authors stated that risk factors including the years of experience and the working hours per week influence hearing. Further study is recommended in the future to reveal risk factors related to dental specialty, working hours and years of experience. 
To decrease the risk of developing noise-induced hearing loss, dental practitioners are encouraged to follow the recommendation of the ADA council on dental materials and devices, which include the following:

Preventive measures for noise attenuation should be directed in three areas: optimum maintenance of rotary equipment, reduction of the ambient noise level in the operatory and personal protection through the use of ear plugs. ${ }^{26}$

Dentists are advised to perform regular annual audiometry check-ups. ${ }^{26}$ This regular testing should identify those who have begun to lose their hearing before they acquire significant auditory impairments. ${ }^{4,21,27}$

It is necessary to produce dental hand pieces with additional noise control. Manufactures are urged to improve quality in terms of decreasing the sound levels produced by high-speed dental hand pieces. Furthermore, friction increases in old and worn machinery, which results in increases in sound levels and highlights the importance of maintenance and periodic replacement. ${ }^{27}$ During the construction and design of the dental clinic, consideration of the use of sound-absorbing materials is also recommended to decrease the noise level. ${ }^{21}$

Continuing education programmes would be beneficial in terms of decreasing the risk of noise-induced hearing loss among dental personnel. Moreover, dental school curricula ought to include education about the different occupational hazards. ${ }^{11}$

\section{CONCLUSION}

Within the limitations of this study, evidence suggests that noise from dental clinics can cause hearing problems, which had a greater effect on the left ear than the right; however, these problems are not severe in nature. Noise-induced hearing loss was more prevalent among the dentists than the control group.

\section{ACKNOWLEDGEMENTS}

This research was supported by Albir Charity Center in Riyadh. The authors thank Riyadh Colleges of Dentistry and Pharmacy for their contribution and support. As well as all of the dentists from King Faisal Specialist Hospital \& Research Center, Prince Sultan Military Medical Centre and Riyadh Colleges of Dentistry and Pharmacy for their cooperation and participation in this research and would also like to express deep gratitude to Magrabi Hospitals and Centers, Riyadh for their support and collaboration. The authors are immensely grateful to Dr Aziza AlJohar, Section Head and Consultant Pediatric Dentist, and Medical Director of the cleft Lip craniofacial programme KFSHRC for sharing her pearls of wisdom during the course of this research.

\section{COMPETING INTERESTS}

The authors declare no conflict of interest.

\section{REFERENCES}

1 Morbidity and Mortality Weekly Report. Leading work-related diseases and injuries--united states. Centers for Disease Control and Prevention 1985 Contract No.: 2.

2 Occupational Safety and Health Administration. Labor UDo. Hearing conservation. OSHA 2002; 3074.

3 Clark WW, Bohne BA. Effects of noise on hearing. JAMA 1999; 281: 1658-1659.

4 Bahannan S, El-Hamid AA, Bahnassy A. Noise level of dental handpieces and laboratory engines. J Prosthet Dent 1993; 70: 356-360.

5 American Speech-Language-Hearing Association. Pure-tone testing c1997-2016 [24 Mar 2016]. Available from: http://www.asha.org/public/hearing/Pure-ToneTesting/.
6 Maggi Soer. Open access guide to audiology and hearing aids for otolaryngologists. University of Cape Town [24 Mar 2016]. Available from: https://vula.uct.ac. za/access/content/group/27b5cb1b-1b65-4280-9437-a9898ddd4c40/Theory\% 20and\%20practice\%20of\%20pure\%20tone\%20audiometry\%20_PTA_pdf.

7 Maico Diagnostics. A guide to otoacoustic emissions (oae's) for physicians 2009 [23 Mar 2016]. Available from: http://www.schoolhealth.com/media/pdf/51057 Physicians_Guide_to_OAEs.pdf.

8 Kumar PR, Sharma P, Kalavathy N, Kashinath K.R. Hearing damage and it's prevention in dental practice. Journal of Dental Sciences and Research. 2011; 2: 32-35.

9 Setcos JC, Mahyuddin A. Noise levels encountered in dental clinical and laboratory practice. Int J Prosthodont 1998; 11: 150-157.

10 Kilpatrick HC. Decibel ratings of dental office sounds. J Prosthet Dent 1981; 45: 175-178.

11 Alwazzan K, Alqahtani M, Alshethri S, Almuhaimeed $\mathrm{H}$, Khan $\mathrm{N}$ et al. Hearing problems among dental personnel. JPDA 2005; 14: 210-214.

12 Torre $\mathrm{P}$ 3rd. Young adults' use and output level settings of personal music systems. Ear Hear 2008; 29: 791-799.

13 Campbell KCM. Otoacoustic emissions (1994-2016). Available from http:// emedicine.medscape.com/article/835943-overview\#showall. Accessed 23 Mar 2016.

14 Jansen EJ, Helleman HW, Dreschler WA, de Laat JA. Noise induced hearing loss and other hearing complaints among musicians of symphony orchestras. Int Arch Occup Environ Health 2009; 82: 153-164.

15 Khaimook W, Suksamae P, Choosong T, Chayarpham S, Tantisarasart R. The prevalence of noise-induced occupational hearing loss in dentistry personnel. Workplace Health Saf 2014; 62: 357-360.

16 Theodoroff SM, Folmer RL. Hearing loss associated with long-term exposure to high-speed dental handpieces. Gen Dent 2015; 63: 71-76.

17 Berger EH. Hearing protector performance: how they work-and-what goes wrong in the real world. 1980. E-A-RLog Series of Technical Monographs on Hearing and Hearing Protection. Indianapolis, IN: 3M Company, pp. 1-4.

18 Dobie RA. Industrial audiometry and the otologist. Laryngoscope 1985; 95 : 382-385.

19 World Health Organization. Prevention of deafness and hearing impairment Thirty Ninth World Health Assemly 1986: Annex A39/14, 31-18.

20 Bali N, Acharya S, Anup N. An assessment of the effect of sound produced in a dental clinic on the hearing of dentists. Oral Health Prev Dent 2007; 5: 187-191.

21 Altinoz HC, Gokbudak R, Bayraktar A, Belli S. A pilot study of measurement of the frequency of sounds emitted by high-speed dental air turbines. J Oral Sci 2001; 43: $189-192$.

22 Dube KJ, Ingale LT, Ingale ST. Hearing impairment among workers exposed to excessive levels of noise in ginning industries. Noise Health 2011; 13: 348-355.

23 Engdahl B, Tambs K. Occupation and the risk of hearing impairment--results from the nord-trondelag study on hearing loss. Scand J Work Environ Health 2010; 36: 250-257.

24 Krishnamurti S. Sensorineural hearing loss associated with occupational noise exposure: effects of age-corrections. Int J Environ Res Public Health 2009; 6: 889-899.

25 Daud MK, Noh NF, Sidek DS, Abd Rahman N, Abd Rani N, Zakaria MN. Screening of dental staff nurses for noise induced hearing loss. B-ENT 2011; 7: 245-249.

26 Noise control in the dental operatory. Council on Dental Materials and Devices. JADA 1974; 89: 1384-1385.

27 Coles RR, Hoare NW. Noise-induced hearing loss and the dentist. Br Dent J 1985; 159: $209-218$

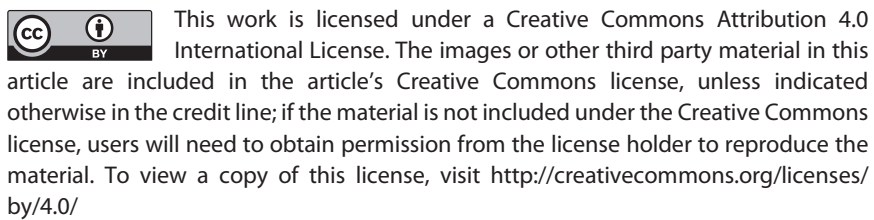

(c) The Author(s) 2016 